\title{
Exploration of Online and Offline Hybrid Teaching of Pathophysiology
}

\author{
Xiaochun Peng1, Lei Wei ${ }^{2 *}$ \\ ${ }^{1}$ Department of Pathophysiology, Health Center, Yangtze University, Jingzhou, China \\ ${ }^{2}$ Department of Pathophysiology, Wuhan University, Wuhan, China \\ Email: ^916038785@qq.com
}

How to cite this paper: Peng, X. C., \& Wei, L. (2021). Exploration of Online and Offline Hybrid Teaching of Pathophysiology. Open Journal of Social Sciences, 9, 433438.

https://doi.org/10.4236/jss.2021.99031

Received: August 27, 2021

Accepted: September 14, 2021

Published: September 17, 2021

Copyright $\odot 2021$ by author(s) and Scientific Research Publishing Inc. This work is licensed under the Creative Commons Attribution International License (CC BY 4.0).

http://creativecommons.org/licenses/by/4.0/

\begin{abstract}
Objective: To explore the construction and application effect of online and offline hybrid teaching of pathophysiology. Methods: The control group used traditional teaching methods and the experimental group used online and offline hybrid teaching methods. The teaching effect, students' satisfaction, learning interest and scientific research ability of the two groups were compared. Results: The total score of the control group was $76.45 \pm 13.22$ and that of the experimental group was $88.35 \pm 14.85(P<0.05)$; The teaching satisfaction of the control group was $85 \%$ and that of the experimental group was $97.5 \%$, which was statistically different $(P<0.05)$; The learning interest and scientific research ability of the experimental group were higher than those of the control group $(P<0.05)$. Conclusion: Online and offline hybrid teaching has effectively improved the teaching effect of pathophysiology, and students' satisfaction has also been improved. At the same time, it improves students' interest in learning and cultivates their scientific research ability.
\end{abstract}

\section{Keywords}

Pathophysiology, Online and Offline, Hybrid Teaching, Traditional Teaching, Reform

\section{Introduction}

Pathophysiology is a science that studies the law and mechanism of disease occurrence, development and prognosis. It is a bridge course between basic medicine and clinical medicine (Liu, 2021). Pathophysiology is added to the basic medicine comprehensive of 2018 medical practitioner examination, which can better reflect that pathophysiology is the basis for learning clinical medicine and provide a theoretical basis for clinical correct understanding and analysis of dis- 
eases (Li, Gu, Zhou, \& Kong, 2018). Pathophysiology is related with physiology, biochemistry, microbiology, immunology and other disciplines. The contents of the chapters from the basic pathological process to the system pathophysiology are linked, which makes it difficult to learn. The traditional teaching method is a single teaching method of "taking teachers as the center and focusing on teaching content", that is, the traditional offline teaching. Offline teaching is dominated by teachers, students receive passively, and lack of learning autonomy and innovation, which is not conducive to the cultivation of students' comprehensive quality and innovation ability. With the rise of network online learning platform and the deepening of information-based teaching, hybrid teaching is to combine the advantages of traditional teaching with the richness of online resources, which can not only play the guiding role of teachers, but also stimulate students' learning initiative, enthusiasm and innovation (Tian, Fu, Zhang, \& Liu, 2021).

Taking the online and offline course of pathophysiology as an example, we elaborate the application of the hybrid teaching mode in medical education, in order to provide reference for the current reform of pathophysiology teaching mode.

\section{Hybrid Teaching Curriculum}

The curriculum reform aims to change the traditional problems of teachers and teaching materials as the center, students' low learning initiative, insufficient cognition and participation through online and offline hybrid teaching; Reconstruct the traditional classroom teaching; Expand the time and space for teaching and learning. Change the current situation of relying on lecturers as a single channel, strengthen continuous learning in the whole process through multiple delivery channels, and cultivate and improve learners' autonomous learning ability, innovative consciousness and critical thinking (Liang, Shi, \& Yuan, 2019). The online basic content covers all chapters of the textbook, highlighting the key points and difficulties. On this basis, guided by medical records and flipping the classroom, the classroom teaching focuses on the improvement of "sorting out knowledge points and cultivating the ability of analysis and judgment". The online expansion also includes research progress, popular science knowledge and expert interviews. Through extracurricular scientific research practice, these key nodes of innovation ability training can be opened up. The organization of offline classroom teaching follows the boppps model and closely focuses on the deepening of course teaching content to realize the internal connection with online expansion and extracurricular scientific research and innovation practice.

\section{Implementation and Evaluation of Hybrid Teaching}

1) Yangtze university is one of the first batch of pilot universities approved by the Ministry of education and the Ministry of health on November 26, 2012. It undertakes the "five-year clinical medicine talent training model reform pilot" project. In 2014, it began to select the first "excellent doctor" teaching reform 
pilot class of clinical medicine specialty (hereinafter referred to as the excellent class). Taking the students of 2018 and 2019 excellent classes of the medical department of Yangtze University as the teaching object, the control group is 40 students of 2018 excellent class, which adopts the traditional teaching mode dominated by teachers' classroom teaching, and the experimental group is 40 students of 2019 excellent class, which adopts the online and offline hybrid teaching mode, The online resource adopts the pathophysiology course offered by Wuhan University on the MOOC platform of Chinese University. The teaching hours of each group are 48 hours, the teaching materials are the ninth edition of pathophysiology in the human health edition, and the allocation of teachers and basic teaching resources is the same; There was no significant difference between the two groups in student source, age, male female ratio and scores of multiple leading courses (such as physiology, anatomy, etc.) $(P>0.05)$.

2) The evaluation includes formative evaluation and questionnaire survey. Formative evaluation mainly carries out online learning evaluation through teaching activities such as discussion, homework, test and question, which accounts for $30 \%$ of the total evaluation score, and the offline final examination accounts for $70 \%$ of the total evaluation score, with a full score of 100 . Through formative evaluation, the teaching goal of mastering the professional knowledge of pathophysiology and having the ability of clinical application is achieved. At the end of the course, the self-designed "pathophysiology online and offline hybrid course questionnaire" was used to conduct a questionnaire survey on the 2018 and 2019 clinical students. The questionnaire includes online teaching resource evaluation, hybrid teaching curriculum satisfaction evaluation and teaching effect satisfaction evaluation.

3) Investigation of students' learning interest and comparison of scientific research ability. Reflect students' interest in learning through students' self-evaluation and after-school discussion. In terms of students' scientific research, it is mainly reflected in the scientific research papers published by the class and the innovation and entrepreneurship projects approved by college level and above students.

4) The data of teaching results and questionnaire survey were statistically analyzed by SPSS 26.0 software. The measurement data were expressed in $\bar{x} \pm s$, the comparison between groups was tested by $t$-test, and the counting data were analyzed by $\chi^{2}$ test.

\section{Teaching Results}

1) According to the analysis of formative evaluation results, there is a statistically significant difference between the two groups in terms of final results and excellent rate $(P<0.05)$, but there is no difference in pass rate $(P>0.05)$, as shown in Table 1. The difference of usual score, final score and total evaluation score was statistically significant $(P<0.05)$, as shown in Table 2.

2) In terms of online teaching resources, the survey shows that $79.58 \%$ of students believe that online resources are helpful or very helpful to learning. In 
terms of hybrid teaching curriculum, $92.54 \%$ of students were satisfied or very satisfied with the online and offline hybrid teaching curriculum. In terms of teaching effect, $97.50 \%$ of the students think that the hybrid teaching effect is better than the traditional teaching effect, higher than $85.00 \%$ of the students who support the traditional teaching, and $P<0.05$, as shown in Table 3.

3) The learning interest and scientific research ability of students have been improved, which is specifically reflected in the increased self interest in learning pathophysiology and related disease research in the experimental group, and the increased discussion of disease mechanism after class; The experimental group has obvious advantages in publishing scientific research papers and applying for major innovation projects, as shown in Table 4.

Table 1. Comparison of passing rate and excellent rate between the two groups.

\begin{tabular}{cccc}
\hline & $\mathrm{N}$ & passing rate (\%) & excellent rate (\%) \\
\hline control group & 40 & 85.00 & 27.50 \\
experimental group & 40 & 97.50 & 62.50 \\
$\chi^{2}$ & & 0.626 & 8.535 \\
$P$ & & 0.429 & 0.003 \\
\hline
\end{tabular}

Table 2. Comparison of usual performance, final performance and total evaluation performance between the two groups $(\bar{x} \pm s)$.

\begin{tabular}{cccc}
\hline & usual performance & final performance & total evaluation performance \\
\hline control group & $85.64 \pm 11.82$ & $72.43 \pm 13.85$ & $76.45 \pm 13.22$ \\
experimental group & $92.73 \pm 12.65$ & $86.54 \pm 15.72$ & $88.35 \pm 14.85$ \\
$t$ & -2.601 & -4.266 & -3.795 \\
$P$ & 0.011 & $<0.001$ & $<0.001$ \\
\hline
\end{tabular}

Table 3. Comparison of teaching satisfaction between the two groups $\mathrm{n}(\%)$.

\begin{tabular}{cccccc}
\hline & $\mathrm{n}$ & Very satisfied & satisfied & dissatisfied & Total satisfaction \\
\hline control group & 40 & $12(30.00)$ & $22(55.00)$ & $6(15.00)$ & $34(85.00)$ \\
experimental group & 40 & $26(65.00)$ & $13(32.50)$ & $1(2.50)$ & $39(97.50)$ \\
$\chi^{2}$ & & & & 11.044 \\
$P$ & & & & 0.004 \\
\hline
\end{tabular}

Table 4. Comparison of learning interest and scientific research ability between the two groups.

\begin{tabular}{ccccc}
\hline & $\begin{array}{c}\text { Agree with } \\
\text { increased interest (n) }\end{array}$ & $\begin{array}{c}\text { Discussion } \\
\text { increase (n) }\end{array}$ & $\begin{array}{c}\text { Scientific research } \\
\text { papers (n) }\end{array}$ & $\begin{array}{c}\text { Project } \\
(\mathrm{n})\end{array}$ \\
\hline control group & 27 & 30 & 3 & 5 \\
experimental group & 36 & 38 & 5 & 7 \\
$\chi^{2}$ & 4.781 & 4.804 & 0.139 & 0.098 \\
$P$ & 0.029 & 0.028 & 0.709 & 0.754 \\
\hline
\end{tabular}




\section{Discuss}

\subsection{Online and Offline Hybrid Teaching Is a Good Exploration for Talent Training}

Talents are the foundation of a powerful country. In order to cultivate high-level academic innovative talents and applied innovative talents, the Ministry of education proposed to implement the "six excellence and one top" plan 2.0 to comprehensively promote the construction of new engineering, new medicine, new agriculture and new liberal arts ( $\mathrm{Hu}, \mathrm{Li}, \mathrm{Li}$, \& Feng, 2021). Online e-learning platforms such as Chinese University MOOC, school online and super star Mu class have brought about a revolution in teaching and learning. Most colleges and universities actively explore the online and offline hybrid teaching mode, so as to complement the advantages of traditional classroom teaching and online teaching, so as to enhance students' autonomous learning ability, innovative spirit and learning effect.

\subsection{The MOOC Course of Wuhan University Gives Us a Good Platform}

The school of basic medicine of Wuhan University has opened the MOOC course of pathophysiology on the online platforms of "University of China MOOC" and "Luojia online". This course was recognized as a first-class undergraduate online course by the Ministry of education in 2020. This subject relies on the open MOOC course resources of Wuhan University to carry out online and offline hybrid teaching, That is, the teaching mode of "pre class guidance $\rightarrow$ Online autonomous learning $\rightarrow$ explanation of key and difficult points in the classroom $\rightarrow$ teacher-student discussion/classroom quiz" is adopted to exercise students' autonomous learning ability and independent thinking ability (Si \& Shu, 2019). The teaching content design includes unit test, chapter test, online final exam and other links, which is convenient to test the learning effect.

\subsection{Online and Offline Hybrid Teaching Has Effectively Improved the Teaching Effect of Pathophysiology}

Compared with the students in the control group who accepted traditional teaching in 2018, 97.5\% of the students in the experimental group who adopted online and offline hybrid teaching in 2019 are willing to accept online and offline hybrid teaching. Hybrid teaching has obvious advantages in cultivating students' learning autonomy, enhancing students' learning interest and expanding students' vision. Taking the inflammatory storm caused by COVID-19 as an example, students can listen to clinicians' lectures by reading the literature, so that students can draw a mind map to illustrate the obstruction of other organs such as liver and kidney function and heart function caused by inflammatory storm. Through online and offline hybrid teaching, students' interest in finding clinical problems and solving problems has been improved and their ability to solve problems has been expanded. Online and offline hybrid teaching students can also master the 
learning initiative, make reasonable arrangements for learning tasks according to their own learning characteristics, and communicate with teachers and students in time to solve difficult problems in time, which improves the learning effect. Curriculum formative evaluation also reflects such advantages. Students in online and offline hybrid teaching classes are better than traditional teaching in peacetime scores, final scores and total evaluation scores. The video cases provided through the network platform are vivid, and the online interactive feedback is also conducive to teachers' timely understanding of students' mastery of knowledge points and timely adjusting teaching settings, so as to further improve teaching quality and students' satisfaction (Huo, Lv, Bian, \& Guo, 2020).

To sum up, online and offline hybrid teaching can effectively improve the teaching quality of pathophysiology, improve students' teaching satisfaction, and improve students' learning interest and scientific research ability.

\section{Acknowledgements}

The present study was supported by the National first-class undergraduate courses obtained by Wuhan University (grant no. 2020110459), the Scientific Research Project of Education Department of Yangtze university (grant no. JY2020134), and the Curriculum Ideology and Politic Project of Graduate School of Yangtze University (grant no. YSZ202111).

\section{Conflicts of Interest}

The authors declare no conflicts of interest regarding the publication of this paper.

\section{References}

Hu, M., Li, Y., Li, J. L., \& Feng, Y. (2021). Reform and Innovation of Talent Training Mode for Medical Laboratory Technology Specialty under the Background of New Medicine. China Higher Medical Education, 3, 63-64.

Huo, L. L., Lv, X. Q., Bian, L., \& Guo, X. Y. (2020). Comparative Study on Online Learning Platforms in Online and Offline Hybrid Teaching Mode. Higher Education, 28, 6061.

Li, B. B, Gu, D. S., Zhou, Y. F., \& Kong, X. (2018). Study on the Status and Role of Pathophysiology in the Qualification examination of Licensed Doctors. Basic Medical Education, 20, 93-95.

Liang, T., Shi, L., \& Yuan, D. P. (2019). Exploration of Online and Offline Hybrid Teaching Mode of Pharmacology. China Continuing Medical Education, 11, 37-39.

Liu, K. D. (2021). Pathophysiology. People's Health Publishing House.

Si, L., \& Shu, C. (2019). Construction and Enlightenment of MOOC Course Principles and Utilization of Information Organization. University Library Work, 39, 42-45.

Tian, L. M., Fu, Y., Zhang, Y., \& Liu, C. F. (2021). Application of Hybrid Teaching under the Background of Internet Plus in Oral Anatomy and Physiology line. China Higher Medical Education, 4, 63-64. 